\title{
Diagnostic Value of C-Reactive Protein/Albumin Ratio to Differentiate Simple Versus Complicated Appendicitis
}

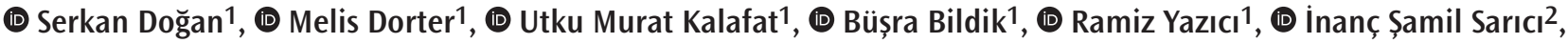 \\ (1) Bașar Cander ${ }^{1}$
}

${ }^{1}$ Clinic of Emergency Medicine, Kanuni Sultan Süleyman Training and Research Hospital, University of Health Sciences Turkey, İstanbul, Turkey ${ }^{2}$ Clinic of General Surgery, Kanuni Sultan Süleyman Training and Research Hospital, University of Health Sciences Turkey, İstanbul, Turkey

\begin{abstract}
Aim: The C-reactive protein (CRP)/albumin ratio is a new inflammation-based prognostic score that correlates with inflammation severity. Objective: The present study investigated the diagnostic value of the CRP/albumin ratio to distinguish between patients with simple and complicated acute appendicitis. This retrospective study was conducted at the University of Health Sciences Turkey, Kanuni Sultan Süleyman Training and Research Hospital, Department of Emergency Medicine, after approval from the ethics committee.

Materials and Methods: A total of 188 patients with acute appendicitis were included. Biochemical parameters, CRP/albumin ratio, ultrasonography (USG) and computed tomography (CT) results, operation findings and length of hospital-stay were compared between patients with simple and complicated appendicitis.

Results: There was no statistically significant difference in terms of leukocyte count, albumin value and diameter of the appendicitis between both USG and CT. The CRP/albumin ratio could specifically differentiate the complicated appendicitis group. The cut-off point of the CRP/ albumin ratio for the diagnosis of complicated appendicitis was 4.4.

Conclusion: The CRP/albumin ratio may be used as a valuable biomarker in the clinical diagnostic process and in treatment planning, particularly to differentiate patients with acute complicated appendicitis from those with non-complicated acute appendicitis.

Keywords: Appendicitis, C-reactive protein, albumin, CRP/albumin ratio, complicated appendicitis
\end{abstract}

\section{Introduction}

Acute appendicitis is a common surgical problem and its lifetime prevalence is around 7\% (1). The basis of treatment in acute appendicitis is based on early diagnosis and emergency surgery. A delay in treatment may cause perforation in the appendix, which may lead to an increase in morbidity and mortality (2). In current clinical practice; physical examination, ultrasonography (USG) and computed tomography (CT) widely used in the diagnoses of acute appendicitis. However, diagnostic failure is often difficult even for experienced surgeons and the rate of negative laparotomy can be up to $30 \%$. Therefore, in the preoperative diagnosis of acute appendicitis, recently, a number of laboratory parameters for inexpensive, effective and rapid diagnosis have been shown to help in the correct diagnosis $(2,3)$.

It is also important to determine whether appendicitis is non-complicated or complicated by the importance of acute appendicitis diagnosis. Because of the fact that acute appendicitis may be complicated in cases where the diagnosis is delayed, the patient's surgical intervention is difficult and even the rate of post-operative complications increases. Therefore, these patients have high rates of readmission, reintervention, postoperative hospital stay, and postoperative complications (4).

C-reactive protein (CRP) are widely used serum inflammatory markers (5). CRP as a positive acute phase reactant is frequently 
used in the diagnosis and follow-up of inflammatory diseases, as well as in the follow-up of postoperative complications and even in the estimation of morbidity and mortality in intensive care setting (6). However, because of its short half-life, CRP alone may not show that acute appendicitis is complicated or noncomplicated.

Serum albumin level is a reliable predictor that is widely recommended in critically ill patients with various diseases that can be measured in the laboratory. As albumin is a negative acute phase protein, it is frequently used in the follow-up of patients with frail, malignancy and malnutrition (7). Although there is a relationship between inflammation and albumin value, there is no use of albumin in the diagnosis of acute appendicitis in routine practice.

The CRP/Albumin ratio is a new inflammation-based prognostic score and it is correlated to the inflammation severity and mortality (8). CRP/albumin ratio has recently been shown to be effective in early diagnosis and treatment of acute cholecystitis, acute pancreatitis, cancer diagnosis, polycystic ovary syndrome and critical care patients. However, there is no study on CRP/ albumin ratio in the diagnosis of acute appendicitis. The present study investigated the diagnostic value of the CRP/Albumin ratio for acute appendicitis patients with evaluation of simple or complicated.

\section{Materials and Methods}

\section{Study Design and Settings}

This study was performed in University of Health Sciences Turkey, University of Health Sciences, Kanuni Sultan Süleyman Training and Research Hospital, Department of Emergency Medicine, it was taken retrospectively with the approval of the ethics committee (no: KAEK/2018.1.21).

\section{Participants}

The data of patients diagnosed with acute appendicitis aged 18 years and older who applied to the study between January 2017-2018 were obtained by scanning the "Hospital Information Management System" and patient files with the approval of the ethics committee.

\section{Data Collected}

Age, gender, complaints, history, hemogram and biochemistry parameters, CRP/Albumin ratio, USG and CT results, operation findings, length of stay, the onset of the complaint and the operation was taken from the data that was filled by the physician who performed the operation on the date, time to the emergency room and recorded in the case data form. The result of histopathology was recorded according to the results of the pathology expert who examined the operation material.

\section{Statistical Analysis}

In the histopathology reports, the results of perforation, abscess, necrosis, gangrene appendicitis were evaluated as complicated appendicitis. Histopathological findings compatible with edematous, inflamed were evaluated as noncomplicated (simple) appendicitis. Patients with hematological, infectious, liver disease and pathology reports indicating a normal appendix or a malignancy were excluded from the study.

All patient data were recorded in the case data form and analyzed in SPSS for Windows 22.0 program. The fit of the parameters to normal distribution was evaluated by Shapiro-Wilks test. Beside of descriptive statistical methods (mean, standard deviation, median, frequency, ratio, minimum, maximum), the Student's t-test was used to compare two groups of variables that showed normal distribution in the comparison of quantitative data. Kruskal-Wallis test and Mann-Whitney $\mathrm{U}$ test with Bonferroni correction were used in the comparison of groups with three or more groups not showing normal distribution. Diagnostic scanning tests (sensitivity, specificity, positive predictive value, negative predictive value) and "Receiver Operator Characteristic" (ROC) curve analysis were used for cut-off determination for parameters. Statistically, 95\% confidence interval, $p<0.05$ was considered significant.

\section{Results}

Total of 188 cases, 135 (71.8\%) patients were male and 53 (28.2\%) patients were female. The mean age of the patients was $33.73 \pm 12$ years, and the median age was 30.5 years. While 166 (88.3\%) cases were non-complicated (simple) appendicitis, 22 (11.7\%) patients were complicated appendicitis. The demographic characteristics of the cases are shown in Table 1.

When we compared the complicated and non-complicated appendicitis groups, there was no statistically significant difference in terms of leukocyte count, albumin value and diameter of the appendicitis in both USG and CT. The time between the onset of the complaint to the operation was found significantly higher in the complicated appendicitis group compared to the noncomplicated appendicitis group ( $p=0.006)$. The median level of CRP is 12.7 (33.75 \pm 50.83 ) in non-complicated group while 52.2 $(90.79 \pm 89.2)$ in complicated group ( $p=0.000)$. Additionally, the median level of CRP/albumin ratio is $2.8(7.69 \pm 12.05)$ in noncomplicated group while $10.8(19.94 \pm 20.05)$ in complicated group $(p=0.000)$ (Table 2$)$.

The ROC curve was drawn for leukocyte and albumin in the diagnosis of complicated appendicitis (Figure 1). Respectively, the area under the curve (AUC) is 0.576, 0.519; the standard error (SE) is 0.07 for both. The area under the ROC curve for both of 


\begin{tabular}{|c|c|c|}
\hline & $\begin{array}{l}\text { Minimum- } \\
\text { maximum } \\
\text { (median) }\end{array}$ & Mean \pm SD \\
\hline Age & $18-73(30.5)$ & $33.73 \pm 12$ \\
\hline Fever & $36-37.5(36.5)$ & $36.41 \pm 0.41$ \\
\hline CRP & $0.1-318.1(15.6)$ & $40.42 \pm 59.26$ \\
\hline Albumin & $3.5-44(4.6)$ & $4.82 \pm 2.89$ \\
\hline CRP/Albumin ratio & $0-75.2(3.4)$ & $9.12 \pm 13.75$ \\
\hline Leukocyte & $\begin{array}{l}3,670-26,140 \\
(15,060)\end{array}$ & $14,724.57 \pm 40,65.2$ \\
\hline $\begin{array}{l}\text { Diameter of appendix } \\
\text { (USG) (mm) }\end{array}$ & $6.4-32(9)$ & $9.68 \pm 2.83$ \\
\hline $\begin{array}{l}\text { Diameter of appendix (CT) } \\
(\mathrm{mm})\end{array}$ & $6-35(11)$ & $11.23 \pm 3.1$ \\
\hline \multirow{2}{*}{$\begin{array}{l}\text { Time between application } \\
\text { and operation (hour) }\end{array}$} & $6-40(13)$ & $14.73 \pm 6.34$ \\
\hline & $\mathrm{n}$ & $\%$ \\
\hline \multicolumn{3}{|l|}{ Gender } \\
\hline Female & 53 & 28.2 \\
\hline Male & 135 & 71.8 \\
\hline \multicolumn{3}{|l|}{ Pathology } \\
\hline Non-complicated & 166 & 88.3 \\
\hline Complicated & 22 & 11.7 \\
\hline
\end{tabular}

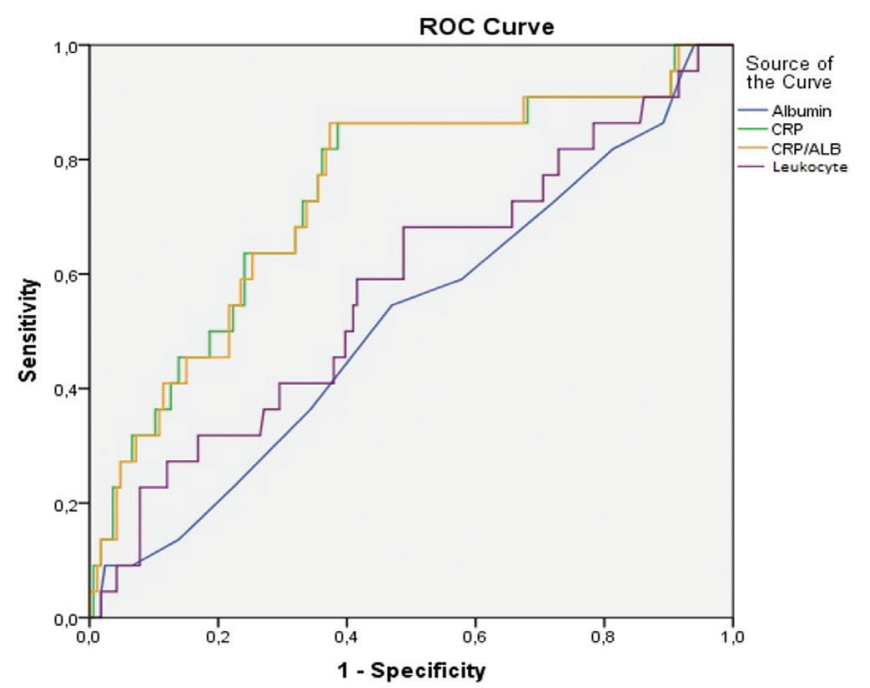

Figure 1. ROC curve to determine the efficacy of albumin, CRP, CRP/albumin ratio, leucocyte levels in the diagnosis of complicated appendicitis

ROC: Receiver operating characteristic, CRP: C-reactive protein, ALB: Albumin

leukocyte and albumin was not significantly higher than 0.5 $(p=0.262, p=0.779$ respectively; $p>0.05)$. The cut-off point for leukocyte and albumin in the diagnosis of complicated was not able to established (Table 3).
The ROC curve was drawn for the CRP/Albumin ratio in the diagnosis of complicated appendicitis. The AUC is 0.737 , the SE is 0.06 . The area under the ROC curve was significantly higher than $0.5(p=0.001)$. The cut-off point for the CRP/Albumin ratio in the diagnosis of complicated appendicitis is $>4.4$. The sensitivity of this value was $86.36 \%$, the specificity was $62.65 \%$, the positive predictive value was $23.46 \%$ and the negative predictive value was $97.2 \%$ (Figure 1, Table 3).

The ROC curve was drawn for CRP in the diagnosis of complicated appendicitis. The AUC is 0.74 , the SE is 0.06 . The area under the ROC curve was found to be significantly higher than $0.5(p=0.001)$. The cut-off point for CRP in the diagnosis of complicated appendicitis was $>19.5$. The sensitivity of this value was $86.36 \%$, specificity $61.45 \%$, positive predictive value $22.89 \%$, negative predictive value $97.14 \%$ (Figure 1, Table 3).

ROC curves were drawn and the areas under the curve were compared in order to determine which parameter as albumin, CRP, CRP/Albumin ratio and Leucocyte were more effective in the diagnosis of complicated appendicitis. The AUC of the albumin $(A \cup C=0.519)$ was found to be significantly lower than that of CRP (AUC $=0.740)$ and CRP/Albumin ratio $(A \cup C=0.737)\left(p_{1}=0.039\right.$; $\left.\mathrm{p}_{2}=0.043 ; p<0.05\right)$. There was no statistically significant difference between albumin and leukocyte areas under the curve $(p=0.484$; $p>0.05)$. There was no statistically significant difference between CRP and CRP/Albumin ratio areas under the curve $(p=0.339$; $p>0.05$ ). Although the AUC of the leukocyte ( $A \cup C=0.576)$ was lower than that of CRP (AUC $=0.740)$ and $C R P / A l b u m i n$ ratio $(A \cup C=0.737)$, this difference was close to significance but not statistically significant $\left(p_{1}=0.073 ; p_{2}=0.080 ; p<0.05\right)$ (Figure 1 , Table 3). The level of 4.4 for CRP/Albumin ratio is 10.624 times higher for non-complicated appendicitis [Odds ratio: 10.624 (95\% confidence interval: 3.021-37.363)].

\section{Discussion}

Acute appendicitis is one of the most common causes of the acute abdomen and one of the most frequent indications for an emergent abdominal surgical procedure worldwide (1). Appendicitis occurs most frequently in the second and third decades of life. The annual incidence is approximately 9.38 per 100,000 population in the United States of America (9). The incidence of negative appendectomy in patients undergoing appendectomy is $13-36 \%$. The possibility of detecting complicated appendicitis during surgery varies between $12-21 \%$.

Clinic of acute appendicitis typically presenting with pain localized to periumbilical region to right lower quadrant. However, the symptoms of the appendicitis vary depending on differences localizations of appendicitis. Although the appendix 


\begin{tabular}{|c|c|c|c|}
\hline & Non-complicated $(n=166)$ & Complicated $(n=22)$ & \multirow[b]{2}{*}{$\mathbf{p}$} \\
\hline & Mean \pm SD (median) & Mean \pm SD (median) & \\
\hline Leukocyte* & $14,581.69 \pm 4,030.61$ & $15,802.73 \pm 4,258.36$ & ${ }^{1} 0.186$ \\
\hline CRP & $33.75 \pm 50.83(12.7)$ & $90.79 \pm 89.2(52.2)$ & ${ }^{2} 0.000 * *$ \\
\hline Albumin & $4.84 \pm 3.07(4.6)$ & $4.65 \pm 0.31(4.7)$ & ${ }^{2} 0.774$ \\
\hline CRP/Albumin ratio & $7.69 \pm 12.05(2.8)$ & $19.94 \pm 20.05(10.8)$ & ${ }^{2} 0.000 * *$ \\
\hline Diameter of appendix (USG) (mm) & $9.46 \pm 1.91(9)$ & $12.11 \pm 7.34(10)$ & ${ }^{2} 0.281$ \\
\hline Diameter of appendix (CT) (mm) & $10.98 \pm 2.38(11)$ & $13.06 \pm 6.03(11)$ & ${ }^{2} 0.193$ \\
\hline Time between onset of complaint and operation (hour) & $14.17 \pm 5.88(13)$ & $18.95 \pm 8.07(20)$ & ${ }^{2} 0.006^{* *}$ \\
\hline
\end{tabular}

Table 3. Cut-off point determination for CRP/Albumin ratio and CRP

\begin{tabular}{|c|c|c|c|c|c|c|c|c|}
\hline & \multirow[b]{2}{*}{ Cut-off } & \multirow[b]{2}{*}{ Sensitivity } & \multirow[b]{2}{*}{ Specifity } & \multirow[b]{2}{*}{$\begin{array}{l}\text { Positive } \\
\text { predictive } \\
\text { value }\end{array}$} & \multirow[b]{2}{*}{$\begin{array}{l}\text { Negative } \\
\text { predictive } \\
\text { value }\end{array}$} & \multicolumn{2}{|l|}{ ROC curve } & \multirow[b]{2}{*}{ p } \\
\hline & & & & & & Area (SE) & $95 \% \mathrm{Cl}$ & \\
\hline CRP/Albumin ratio & $>4.4$ & 86.36 & 62.65 & 23.46 & 97.20 & $0.737(0.06)$ & 0.668-0.799 & $0.001 *$ \\
\hline CRP & $>19.5$ & 86.36 & 61.45 & 22.89 & 97.14 & $0.740(0.06)$ & $0.671-0.801$ & $0.001^{*}$ \\
\hline Leukocyte & - & - & - & - & - & $0.576(0.07)$ & $0.502-0.648$ & 0.262 \\
\hline Albumin & - & - & - & - & - & $0.519(0.07)$ & $0.445-0.592$ & 0.779 \\
\hline
\end{tabular}

has a retrocecum at a rate of $65-70 \%$, it may also have different localizations, such as subcecum, paracolic and paraileal (10). Because of these differences and change in the acute appendicitis clinic from patient to patient, some findings and scoring methods have been described. McBurney's (11) point tenderness is described as maximal tenderness at 3-5 cm from the anterior superior iliac spine on a straight line to the umbilicus with a $72 \%$ sensitivity and $80 \%$ specificity. Additionally, Rovsing's sign refers to pain in the right lower quadrant with palpation of the left lower quadrant. This sign is also called indirect tenderness and is indicative of right-sided local peritoneal irritation with a $45 \%$ sensitivity an $77 \%$ specificity (12). The most popular of the scoring systems and the most commonly used is the modified Alvarado scale. A low Alvarado score $(<4)$ has more diagnostic utility to "rule out" appendicitis than a high score $(\geq 7)$ does to "rule in" the diagnosis. Unfortunately, a high score $(\geq 7)$ alone had poor diagnostic utility, as the overall specificity was $81 \%$ (13).

Imaging is used mainly to increase the specificity of the diagnostic evaluation for appendicitis and to decrease the negative appendectomy rate. CT demonstrates higher diagnostic accuracy than ultrasound or MRI. An enlarged fluid-filled appendix ( $>7$ $\mathrm{mm}$ in diameter) is considered an abnormal finding, while an appendix with a diameter of 6 to $7 \mathrm{~mm}$ is considered an inconclusive finding. However, $\mathrm{CT}$ is contraindicated in patients with pregnancy, renal insufficiency and hypersensitivity reaction to iodinate contrast (14). On the other hand, tomography and ultrasound are not found in many centers especially in rural areas and night shift conditions. This led the clinician to detect inflammation caused by acute appendicitis by different laboratory parameters.

There are many studies in the literature about laboratory values for the diagnosis of acute appendicitis. It has been emphasized that many parameters such as neutrophil/lymphocyte ratio, platelet/ lymphocyte ratio, mean platelet volume, red cell distribution width, D-lactate level, procalcitonin and many interleukins are important in the diagnosis of acute appendicitis $(15,16)$. Another issue as important as the diagnosis of appendicitis is whether appendicitis is complicated or not. As is known, the morbidity and mortality of complicated appendicitis is higher than noncomplicated appendicitis. Eddama et al. (17) found CRP values significant in the diagnostic distinctions of non-complicated and complicated appendicitis. Additionally, in previously studies red cell distribution width and eosinopenia accompanied by higher neutrophil and leukocyte counts were defined as useful biomarkers in perforated appendicitis $(18,19)$. Pham et al. (20) found high leukocyte counts in necrosis or perforated appendicitis. In the study performed by Kim et al. (8), CRP and INR levels were estimated in the diagnosis of complicated appendicitis and it 
was found to be significantly higher in patients with complicated appendicitis. In the study of Shelton et al. (21), it was seen that the rate of postoperative complications increased in patients with high preoperative CRP levels. In our study, complicated and non-complicated appendicitis groups have no differences in terms of leukocyte count, albumin value and diameter of the appendicitis in both USG and CT. The time between the onset of the complaint to the operation was found significantly higher in the complicated appendicitis group compared to the noncomplicated appendicitis group.

CRP is a positive acute phase protein and increases in inflammation; since serum albumin is a negative acute phase protein (7). Therefore, it was thought that CRP/Albumin ratio would show inflammation more specific than CRP alone. In the case of an inflammation, the increase in CRP/Albumin ratio in patients is an expected result in the normal course of the disease. Therefore, CRP/albumin ratio has recently been shown to be effective in early diagnosis and treatment of acute cholecystitis, acute pancreatitis, cancer diagnosis, polycystic ovary syndrome and critical care patients. However, there is no study showing the relationship between this value and acute appendicitis. In our study, we examined the correlation between histopathologically diagnosed acute appendicitis and CRP/albumin ratios in patients with complicated and non-complicated appendicitis. According to our results, the median level of CRP is significantly higher in complicated group. The cut-off point for CRP in the diagnosis of complicated appendicitis was $>19.5$. Additionally, the median level of CRP/albumin ratio is 2.8 (7.69 \pm 12.05$)$ in non-complicated group while $10.8(19.94 \pm 20.05)$ in complicated group $(p=0.000)$. We also found cut-off point for the CRP/albumin ratio in the diagnosis of complicated appendicitis is $>4$.4. The level of 4.4 for CRP/albumin ratio is 10.624 times higher for non-complicated appendicitis.

\section{Conclusions}

Cut-off values of laboratory tests in acute appendicitis cases can help diagnosis and treatment planning. We think that increased CRP/albumin ratio may be used as a valuable biomarker in clinical diagnostic process and treatment planning, especially to differentiate complicated or non-complicated setting.

\section{Ethics}

Ethics Committee Approval: This study was performed in University of Health Sciences Turkey, University of Health Sciences, Kanuni Sultan Süleyman Training and Research Hospital, Department of Emergency Medicine, it was taken retrospectively with the approval of the ethics committee (no: KAEK/2018.1.21).
Informed Consent: Retrospective study.

Peer-review: Externally peer-reviewed.

\section{Authorship Contributions}

Surgical and Medical Practices: I.S.S., Concept: S.D., M.D., U.M.K., I.S.S., B.C., Design: S.D., U.M.K., I.S.S., B.C., Data Collection or Processing: M.D., R.Y., Analysis or Interpretation: S.D., M.D., B.B., R.Y., Literature Search: M.D., U.M.K., B.B., Writing: S.D., B.B., R.Y., B.C.

Conflict of Interest: No conflict of interest was declared by the authors.

Financial Disclosure: The authors declared that this study received no financial support.

\section{References}

1. Shogilev DJ, Duus N, Odom SR, Shapiro NI. Diagnosing appendicitis: evidence-based review of the diagnostic approach in 2014. West J Emerg Med. 2014;15:859-71.

2. Keskek M, Tez M, Yoldas O, Acar A, Akgul O, Gocmen E, et al. Receiver operating characteristic analysis of leukocyte counts in operations for suspected appendicitis. Am J Emerg Med. 2008;26:769-72.

3. Guler K, Tihan DN, Duman U, Dandin Ö, Dilektaşlı E, Erol F, et al. Are Preoperative serum C-reactive Protein and Leucocyte Values Useful to Predict the Perforation in Patients with Acute Appendicitis? Turk J Colorectal Dis. 2016;26:6-12.

4. Nimmagadda N, Matsushima K, Piccinini A, Park C, Strumwasser A, Lam L, et al. Complicated appendicitis: Immediate operation or trial of nonoperative management? Am J Surg. 2019;217:713-7.

5. Devran 0, Karakurt Z, Adıguzel N, Güngör G, Yazıcıoğlu Moçin 0, Kalamanoğlu Balcı M, et al. C-reactive protein as a predictor of mortality in patients affected with severe sepsis in intensive care unit. Multidiscip Respir Med. 2012;7:47

6. Soltani F, Pipelzadeh MR, Akhondzadeh R, Rashidi M, Ekrami A. Evaluation of C-reactive Protein, Albumin and the C-reactive Protein/Albumin Ratio as Prognostic Markers in Trauma Patients Admitted to Intensive Care Unit. BJMMR. 2016;12:1-7

7. Roberts I, Blackhall K, Alderson P, Bunn F, Schierhoutet G. Human albumin solution for resuscitation and volume expansion in critically ill patients. Cochrane Database Syst Rev. 2011;10:CD001208.

8. Kim M, Kim SJ, Cho HJ. International normalized ratio and serum C-reactive protein are feasible markers to predict complicated appendicitis. World J Emerg Surg. 2016;11:31.

9. D’Souza N, Nugent K. Appendicitis. Am Fam Physician. 2016;93:142-3.

10. Jaffe BM, Berger DH. The appendix. In: Schwartz's Principles of Surgery, 8th ed, Schwartz SI, Brunicardi CF editors, McGraw-Hill Companies, New York; 2005.

11. McBurney C. Experience with early operative interference in cases of disease of the vermiform appendix. NY Med J. 1889;50:676.

12. Jahn H, Mathiesen FK, Neckelmann K, Hovendal CP, Bellstrøm T, Gottrup F. Comparison of clinical judgment and diagnostic ultrasonography in the diagnosis of acute appendicitis: experience with a score-aided diagnosis. Eur J Surg. 1997;163:433-43.

13. Ohle R, O'Reilly F, O’Brien KK, Fahey T, Dimitrov BD. The Alvarado score for predicting acute appendicitis: a systematic review. BMC Med. 2011;9:139.

14. Yun SJ, Ryu CW, Choi NY, Kim HC, Oh JY, Yang DM. Comparison of Low- and Standard-Dose CT for the Diagnosis of Acute Appendicitis: A Meta Analysis. AJR Am J Roentgenol. 2017;208:W198-207. 
15. Al-Abed YA, Alobaid N, Myint F. Diagnostic markers in acute appendicitis. Am J Surg. 2015;209:1043-7.

16. Aydin OU, Soylu L, Dandin O, Uysal Aydin E, Karademir S. Laboratory in complicated appendicitis prediction and predictive value of monitoring. Bratisl Lek Listy. 2016;117:697-701.

17. Eddama M, Fragkos KC, Renshaw S, Aldridge M, Bough G, Bonthala L, et al. Logistic regression model to predict acute uncomplicated and complicated appendicitis. Ann R Coll Surg Engl. 2019;5:107-18.

18. Ertekin B, Kara H, Erdemir E, Doğan E, Acar T, Demir LS. Efficacy of Use of Red Cell Distribution Width as a Diagnostic Marker in Acute Appendicitis. Eurasian J Emerg Med. 2017;16:29-33.
19. Akay S, Akay H, Vardar E, Erkul Z. Comparison of Eosinophil Values with Other Biomarkers in Predicting Perforation of Acute Appendicitis. Eurasian J Emerg Med. 2017;16:8-11.

20. Pham XD, Sullins VF, Kim DY, Range B, Kaji AH, de Virgillo CM, et al. Factors predictive of complicated appendicitis in children. J Surg Res. 2016;206:62-6.

21. Shelton JA, Brown JJ, Young JA. Preoperative C-reactive protein predicts the severity and likelihood of complications following appendicectomy. Ann R Coll Surg Engl. 2014;96:369-72. 